\title{
Synergistic effect of organophoshate chlorpyrifos and synthetic pyrethroid cypermethrin in freshwater commercially cultivable fish Labeo rohita
}

\author{
R.Saravanan $\varpi^{1}$, R.Sivachandran ${ }^{2}$, R.Muthulakshmi ${ }^{3}$ and K.Revathi ${ }^{2}$
}

Received: 15.11.2012

Accepted: 18.02.2013

\begin{abstract}
In the present study freshwater commercially cultivable Indian major carp Labeo rohita fingerlings was used to evaluate the synergistic effect of chlorpyrifos, an organophosphate insecticide and cypermethrin, a synthetic pyrethroid insecticide widely used in agricultural fields. The fishes were maintained at sublethal concentration for a period of 14 and 21 days. Histological examination was carried out in gills, liver and muscle at the end of exposure period to study the extent of damage at safe concentration.
\end{abstract}

Keywords: Chlorpyrifos, Cypermethrin, gills, liver, muscle, Labeo rohita

\section{Introduction}

World wide pesticide usage has increased dramatically during the past two decades coinciding with changes in farming practices and increasingly intensive agriculture (ICMR bulletin, 2001). Contamination of surface waters has been well documented world wide and constitutes a major issue at local, regional, national and global levels (Glaser, 2006). The landscape in a single river catchment may have a variety of agricultural uses where a number of different crop protection programs are employed. Agricultural practices can include pesticides being mixed during application Therefore aquatic non-target organisms are exposed to multiple stressors including pesticides and their degradation products both simultaneously and consecutively (Wang et al ., 2009a ; Colovic et al ., 2011). During the south west monsoon just after the sowing of rice crops these pesticides enter the fish pond as run off and they persist at very low concentrations in pond water (Tilak et al ., 2005b). Repeated exposures and multiple stressors such as pesticides mixtures have clear relevance to real

\footnotetext{
Author's Address

${ }^{1}$ Post Graduate Department of Advanced Zoology and Biotechnology, Dr Ambedkar Government Arts College, Vyasarpadi, Chennai, Tamilnadu, India

${ }^{2}$ Department of Advanced Zoology and Biotechnology, R.K.M.

Vivekananda College, Chennai, Tamilnadu, India

${ }^{3}$ Post Graduate and Research Department of Advanced Zoology and Biotechnology, Ethiraj college for women, Chennai, Tamilnadu, India E-mail: rsaravanan2@yahoo.com
}

situations, it is necessary to understand their effects on non-target organisms (Ashauer et al., 2006; 2007c) so that appropriate risk assessment methodology can be developed. Zhang et al (2010) reported effects on the $96 \mathrm{hr}$ LC50 in Zebrafish (Brachydanio rerio) exposed to binary combinations of pyrethroid insecticides permethrin, bifenthrin, tetramethrin and etofenprox with the organophosphorus insecticides dichlorvos or phoxim. Chlorpyrifos is a broad spectrum organophosphate insecticide which is effective in controlling insect pests (RED, 2006). Cypermethrin is extensively used in agriculture, having potent insecticidal action with tremendous potential to kill insect pest (Laskowski, 2002). Chlorpyrifos does nor partition easily from soil to water, Therefore chlorpyrifos found in runoff water is likely a result of soil bound chlorpyrifos from eroding soil rather than from dissolved chlorpyrifos ( kamrin, 1999). It is highly toxic to freshwater fishes and potential to bioaccumulate in the tissues as metabolites 3, 5, 6 Trichloro- 2- pyridinol (TCP). Pyrethroids are metabolized and eliminated more slowly by fish than mammals which may explain this compounds higher toxicity (Aydin et al., 2005). Generally the lethality of pyrethroids to fish increase with increasing octanol/water partition coefficients (Amweg et al., 2005). The differences in the scale of interactions between pyrethroids and 
organophosphorus insecticides depends on both the strength of the interaction between the organophosphate and carboxylesterases and the importance of the carboxylesterase in the metabolic degradation of the pyrethroid (Groner and Relyea, 2011).The outcome of the present study would decipher the impact of low concentrations and synergistic effect of organophosphate chlorpyrifos and synthetic pyrethroid cypermethrin. It would also ascertain whether these pesticides when present in combined doses in ambient water would have deleterious effect on various organs. The tissues chosen for the study were gills which are involved in respiration and osmoregulation. Liver the site of metabolic activities and biotransformation of xenobiotics and muscle which form the edible portion and providing the best source of protein in the diet.

\section{Material and Methods}

Selection of experimental animals : Fresh water edible carp Labeo rohita fingerlings with average weight of $15 \pm 2$ gms and $12 \pm 3 \mathrm{cms}$ in length was used as experimental animal to evaluate the combined effect of organophosphate and pyrethroid pesticide which is widely used for agricultural application.The fishes were procured from Seed Fish India, Budur village , Thiruvallur district. They were transported to the laboratory in oxygen filled polythene bags and acclimatized for a period of two weeks in glass aquaria with normal photoperiod and aeration. Water was renewed every 24 hour to maintain healthy environment of the fish and to remove the feed remains and nitrogenous waste products. They were fed with commercially available feed one hour prior to water exchange.Feeding was stopped 24 hour prior to experimentation.

Experimental Design: Formulated mixture of the two pesticide used in the study was supplied by Toxicology Division, Rallis India, Bangalore for evaluating the toxic effect on edible carp Labeo rohita. To determine the 96 hrs $\mathrm{LC}_{50}$ static renewable bioassay method was adopted (Sprague, 1973) and $96 \mathrm{hr} \mathrm{LC}_{50}$ was determined by probit analysis method.The $\mathrm{LC}_{50}$ was found to be 0.05 $\mathrm{mg} / \mathrm{L}$. The fishes were exposed for a period of 14 and 21 days at one fifth the sublethal concentration $(0.01 \mathrm{mg} / \mathrm{L})$.The fishes were divided into 2 groups with five fishes in each group. Group I: Control fishes in toxicant free water, Group II: Fishes maintained in $0.01 \mathrm{mg} / \mathrm{L}$ of pesticide mixture for a period of 14 days. Group III: Fishes maintained in $0.01 \mathrm{mg} / \mathrm{L}$ of pesticide mixture for a period of 21 days.

Collection of tissues for histological studies: The animals were sacrificed and various tissues gills, liver and muscle was separated and immediately fixed in Bouin's fluid for histological studies following the method of Roberts (1978) and Humanson (1979).The sections were stained with haematoxylin and eosin.

\section{Results and Discussion}

Histological studies of the various tissues exposed to the combined mixture of chlorpyrifos and cypermethrin showed mild to extensive changes during different days of exposure. In control fishes the gills appear to be normal with primary and secondary lamella (Fig 1a). When the fishes were exposed to the combined mixture of the pesticide for 14 days gills showed epithelial damage, lamellar swelling, hyperplasia and hypertrophy (Fig 1 b). During 21 days of exposure disruption of secondary lamella was observed (Fig 1 c).Normal liver is shown in (Fig 2a). Small vacuoles in the hepatic cells were noted along with degeneration of cytoplasm and places with area of diffuse necrosis on the $14^{\text {th }}$ day (Fig 2b). Sinusoids were distended and central vein appeared severely damaged on the $21^{\text {st }}$ day (Fig 2c). Normal muscle tissue (Fig 3a).On the $14^{\text {th }}$ day of exposure muscle mass showed reduction and degeneration of muscle (Fig 3b). During 21 days of exposure dystrophic changes , thickening, separation of muscle bundles, and infiltration of white cells was observed (Fig 3c). There have been a number of studies in fish assessing the toxicity of combinations of pesticides. The toxicity of most combinations was at most additive (Olmstead and Leblanc, 2005; Relyea, 2009; Norgaard and Cedergreen, 2010). Synergy could be linked in many cases to the mode of action of the pesticide (Pereira et al., 2009). Organophosphorus insecticides synergise pyrethroid insecticides for which the carboxylesterases are major route of metabolism through inhibition of the enzyme (Laetz et al., 2009). One of the advantages of using histopathological biomarkers in environmental monitoring is that this category of biomarkers allows examining specific target organs that are responsible for respiration, detoxification and coordination (Navraj and Yasmin, 2012). 


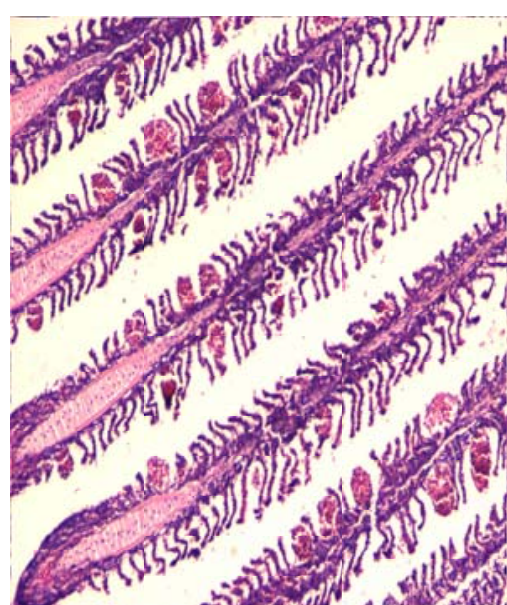

1 (a)

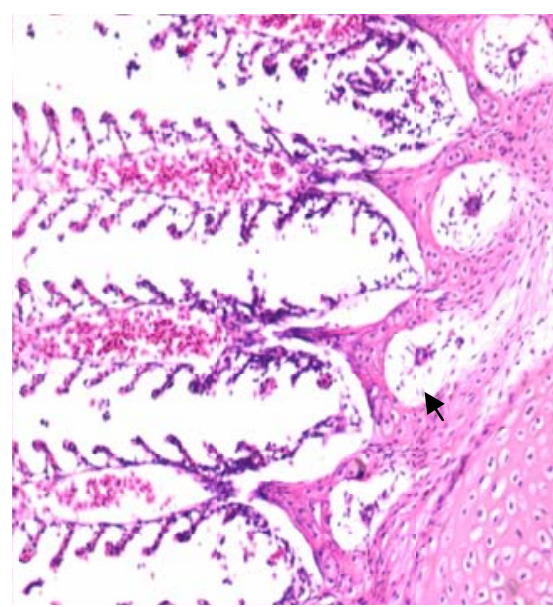

1 (b)

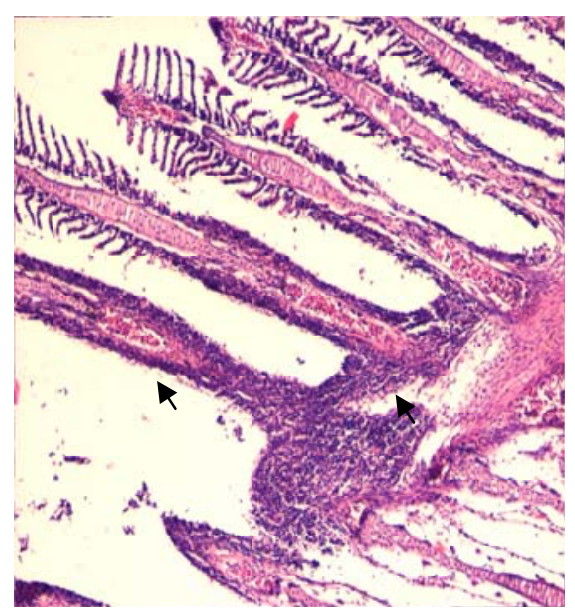

1 (c)

Fig. 1(a) Showing normal gill structure of Labeo rohita. Fig.1(b) \& 1(c) Showing gills with epithelial lifting and damage to secondary lamella and lamellar hyperplasia

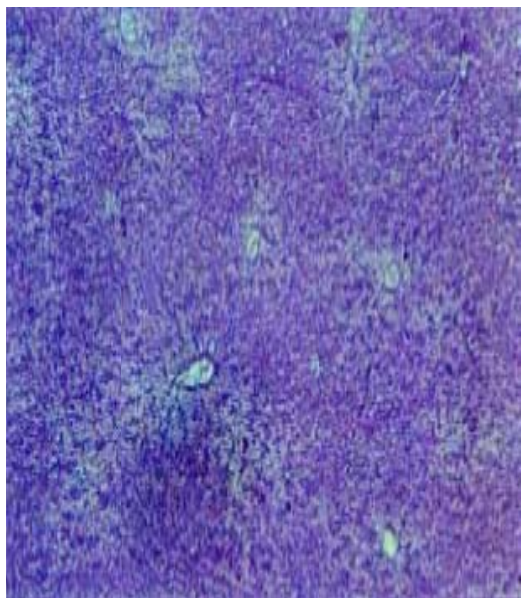

2 (a)

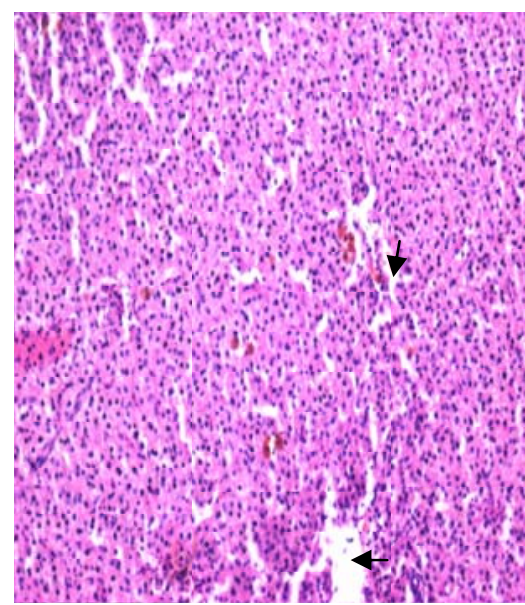

2(b)

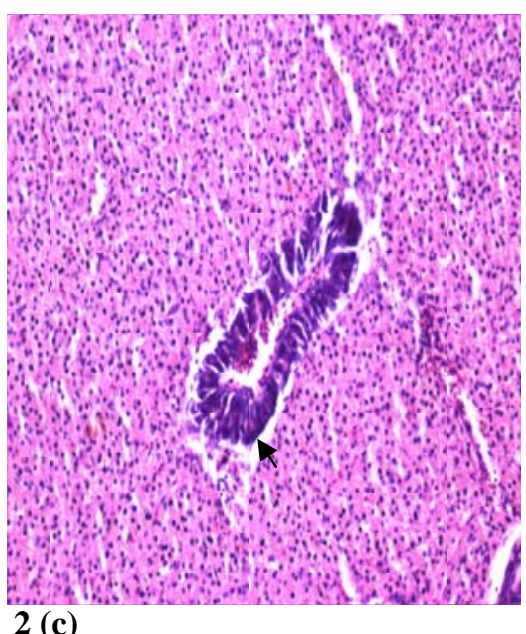

2 (c)

Fig. 2(a) Showing normal liver structure of Labeo rohita. Fig.2(b) \& 2(c) Showing swelling of hepatocytes, vacuolation, infiltration and hepatic necrosis

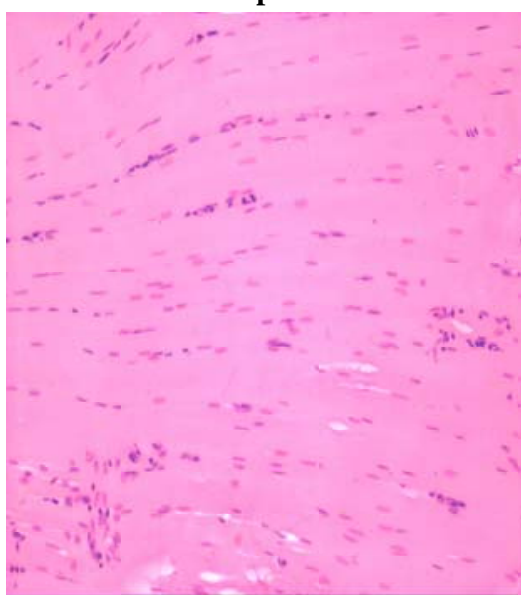

3(a)

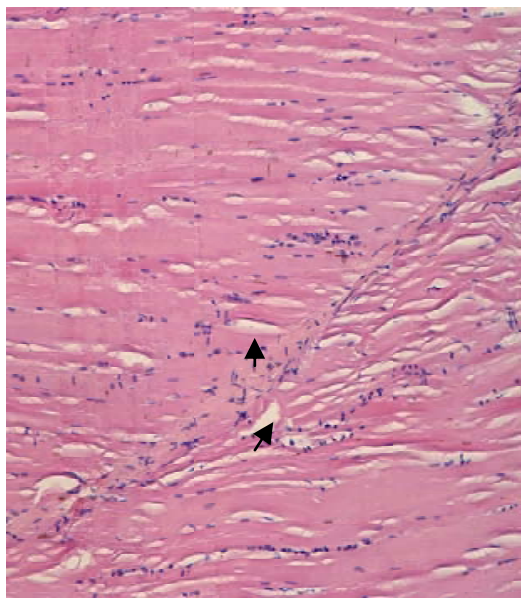

3(b)

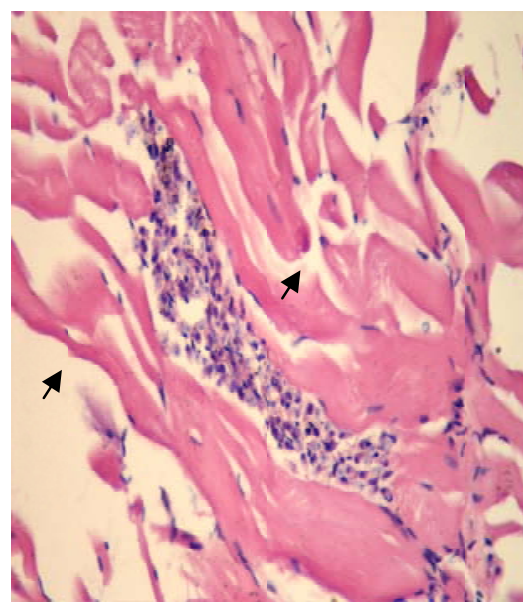

3(c)

Fig. 3(a) Showing normal muscle bundles of Labeo rohita . Fig.3(b) \& 3(c) Showing thickening and separation of muscle bundles and intra muscular edema 
Accumulation and biotransformation of xenobiotics in fish can be ascertained through this (Vander Oost et al., 2003).Gills are the primary site of gaseous exchange, acid base regulation and ion transfer (Randall, 1990). Histological changes were characterized by damage in epithelial cells and hyperplasia, lamellar swelling. The changes are indicative of diminished oxygen supply resulting in hypoxic respiratory response, although not lethal gill damage caused by environmental pollutants is important from the aspect of morbidity as it retards growth and affects reproduction (Das and Mukherjee, 2000). Similar results were also observed in gills of Cyprinus carpio exposed to monocrotophos (Johal et al ., 2007)Liver is the primary organ for detoxification of organic xenobiotics.The liver tissue shows alteration in parenchyma, cytoplasm of hepatocytes displayed vacuoles that appeared as clear vesicles occupying the whole cytoplasm and necrosis. It appears to be a general feature of the liver of intoxicated fish that the degree of structural heterogeneity is enhanced with the concentration of the toxicant (Das and Mukherjee, 2000). Similar results have been reported in Clarias gariepinus exposed to lead (Olojo et al 2005). Muscle tissue showed extensive changes showing marked thickening and separation of muscle bundles in the present study. This could have been due to hyperactivity and excitability with subsequent muscular fatigue (Das and Mukherjee, 2000)Belden and Lydy (2006) assessed the effects of combined chlorpyrifos and esfenvalerate toxicity in fathead minnows Pimephales promelas to determine the applicability of independent action and concentration addition models for predicting toxicity. They reported more than additive toxicity when fish were exposed to the combination even at very low concentrations of chlorpyrifos. This increased toxicity was suggested to be due to the decreased metabolism of the pyrethroid due to the inhibition of the carboxylesterase activity.

\section{Conclusion}

The present study suggests that combination of mixtures and the mode of action of these compounds are susceptible to high degree of damage even at very low amount of toxicant present in ambient waters. Though the low concentrations of toxicants in the water may be considered within safe limits, still the vital organs are adversely affected which may interfere with growth, development, physiological functioning and reproduction. Further investigation is required to develop a greater understanding of the species, dose and time dependence of exposure to pesticide mixtures in which more complex interactions occur to allow prediction of the scale of synergistic interactions.

\section{References}

Amweg, E.L., Weaton, D.P. and Ureda, N.M . 2005. Use and toxicity of pyrethroid pesticides in the Central Valley, California,USA. Environonment Toxicology and Chemistry, 24 : 966-972.

Ashauer, R. , Boxall, A. B. A. and Brown , C. D. 2006. Predicting effects on aquatic organisms from fluctuating or pulsed exposure to pesticides. Environmental Toxicology and Chemistry, 25 (11) : 1899.

Ashauer, R., Boxall , A. B. A. and Brown ,C. D. 2007c. Modeling combined effects of pulsed exposure to carbaryl and chlorpyrifos on Gammarus pulex. Environmental Science and Technology, 41(15): 5535-5541.

Aydin, R., Koprucu, R., Dorucu, M., Koprucu, S. S. and Pala, M. 2005. Acute toxicity of synthetic pyrethroid cypermethrin on the common carp Cyprinus carpio embryos and larvae Aquaculture International , 13(5) : 451-458

Belden , J . B . and Lydy, M. J. 2006. Joint toxicity of chlorpyrifos and esfenvalerate to fathead minnows and midge larvae. Environonment Toxicology and Chemistry, 25: 623-629.

Colovic, M. B., Krstic , D. Z. , Uscumlic, G.S. and Vasic ,V. M . 2011. Single and simultaneous exposure of acetyl cholinesterase to diazinon, chlorpyrifos and their photodegradation products. Pesticide Biochemistry and Physiology ,100(1): 16-22.

Das, B.K. and Mukherjee, S. C. 2000. A histopathological study of carp Labeo rohita exposed to hexachlorocyclohexane. Veterinarski Archives ,70(4) 169-180

Glaser, A. 2006. Threatened waters.Turning the tide on pesticide contamination. Beyond pesticides, 1(2): 2-5.

Groner, M.L. and Relyea, R.A. 2011. A tale of two pesticides: How common insecticides affect aquatic communities. Freshwater Biology, 6(11): 2391-2404.

Humanson, G. L (4 ${ }^{\text {th }}$ ed ) 1979. Animal tissue technique WH Freeman and Company San Francisco, USA pp 3-63.

ICMR Bulletin, 2001. Pesticide pollution.Trends and perspective, 3(1) : 1-12.

Johal, M. S., Sharma , M. L. and Ravneet . 2007. Impact of low dose of organophosphate monocrotophos on the epithelial cells of gills of Cyprinus carpio communis Linn -SEM study. Journal of Environmental Biology, 28(3) : 653-667. 
Kamrin, M. A. 1997 .Pesticide Profiles Toxicity, Environmental Impact, and Fate; Lewis Publishers, Boca Raton, Florida; pp 147- 152.

Laetz, C. A., Baldwin, D. H., Collier, T. K., Hebert, V., Stark, J. D., Scholz,N. L. 2009. The Synergistic Toxicity of Pesticide Mixtures: Implications for Risk Assessment and the Conservation of Endangered Pacific Salmon. Environmental Health Perspectives 117(3): 348-353.

Laskowski, D.A. 2002. Physical and chemical properties of pyrethroids. Review of Environmental Contamination and Toxicology, $174: 49-170$

Navaraj ,P. S. and Yasmin, J. 2012. Toxicological evaluation of tannery industry waste water on Oreochromis mossambicus. African Journal of Environmental Science and Technology, 6(9) : 331-336

Norgaard, K. B. and Cedergreen, N. 2010. Pesticide cocktails can interact synergistically on aquatic crustaceans. Environmental Science and Pollution Research, 17(4): 957-967

Olmstead, A. W. and LeBlanc, G. A. 2005. Toxicity assessment of environmentally relevant pollutant mixtures using a heuristic model. Integrated Environmental Assessment and Management, 1: 114-122.

Olojo , E. A., Olurin, K. B., Mbaka, G. and Oluwemimo, A. D . 2005. Histopathology of the gill and liver tissues of the African catfish Clarias gariepinus exposed to lead. African Journal of Biotechnology, 4 : 117-122

Pereira ,J. L., Mendes, C. D. and Goncalves F. 2009. Acute and chronic effects of a mixture of formulated pesticides and its corresponding active ingredients in Daphnia magna. Fresenius Environmental Bulletin , 18(7b) : 1281-1288.

Randall, D. J. 1990. Control and coordination of gas exchange in water breathers. Advances in Comparative Environmental Physiology , $6: 253-278$
Reregistration Eligibility Decision (RED) for Chlorpyrifos; 2006 U.S Environmental Protection Agency, Office of Prevention, Pesticides and Toxic Substances, Office of Pesticide Programs, U.S. Government Printing Office: Washington, DC.

Relyea ,R. A. 2009. A cocktail of contaminants: how mixtures of pesticides at low concentrations affect aquatic communities. Oecologia , 159(2): 363-376.

Roberts, R. J. ( $1^{\text {st }}$ ed) 1978. The pathophysiology and systemic pathology of teleosts and laboratory methods.In : Fish Pathology . Bailliere Tindall London ,UK , pp 235-246

Sprague, J . B . 1973 .Measurement of pollutant toxicology of fish.Sublethal effects and safe concentration .Water Research , 5 : 245-266

Tilak, K. S., Veeraiah and Koteeswara Rao, 2005b. Biochemical changes induced by chlorpyrifos an organophosphate compound in sublethal concentrations to freshwater fish Catla catla, Labeo rohita and Cirrhinus mrigala. Journal of Environmental Biology, 26: 341-347

Van der Oost, R. , Beyer, J. and Vermeulen , N.P.E. 2003. Fish bioaccumulation and biomarkers in environmental risk assessment. A review. Environmental Toxicology and Pharmocology, 13 : 57-149

Wang , C ., Lu , G. , Cui , J. and Wang, P. 2009a. Sublethal effects of pesticide mixtures on selected biomarkers of Carassius auratus. Environmental Toxicology and Pharmacology , 28(3): 414-419.

Zhang, Y., Liu, S., Liu, H. and Liu, Z. 2010. Evaluation of the combined toxicity of 15 pesticides by uniform design. Pest Management Science, 66(8): 879-887. 